\title{
Comparison of State Prevention of Mother-To-Child Transmission of HIV and National Biennial ANC HIV Sentinel Surveillance Data: Ten Year Experience from Gombe State, North East Nigeria
}

\author{
Elon Warnow Isaac1 ${ }^{*}$, Alfred Annabi Massa ${ }^{2}$, Suraj Abdulkarim³ ${ }^{3}$ Ayomikun Ajani ${ }^{4}$, \\ Christiana Oyeniyi ${ }^{5}$
}

\author{
${ }^{1}$ Department of Paediatrics, College of Medical Sciences, Gombe State University/Federal Teaching Hospital, Gombe, Nigeria \\ ${ }^{2}$ Department of Obstetrics \& Gynaecology, College of Medical Sciences, Gombe State University/Federal Teaching Hospital, \\ Gombe, Nigeria \\ ${ }^{3}$ Gombe State Agency for the Control of AIDS, Gombe, Nigeria \\ ${ }^{4}$ Department of Paediatrics, Federal Teaching Hospital, Gombe, Nigeria \\ ${ }^{5}$ Infectious Disease Training and Research, Gombe, Nigeria \\ Email: *drwarnow@yahoo.com
}

How to cite this paper: Isaac, E.W., Massa, A.A., Abdulkarim, S., Ajani, A. and Oyeniyi, C. (2020) Comparison of State Prevention of Mother-To-Child Transmission of HIV and National Biennial ANC HIV Sentinel Surveillance Data: Ten Year Experience from Gombe State, North East Nigeria. World Journal of AIDS, 10, 1-14. https://doi.org/10.4236/wja.2020.101001

Received: November 19, 2019

Accepted: February 7, 2020

Published: February 10, 2020

Copyright $\odot 2020$ by author(s) and Scientific Research Publishing Inc. This work is licensed under the Creative Commons Attribution International License (CC BY 4.0).

http://creativecommons.org/licenses/by/4.0/ (c) (i) Open Access

\begin{abstract}
There are significant variations in PMTCT programme implementation in the country. Biennial serosentinel survey among pregnant women attending antenatal clinics provides estimates of HIV and for monitoring the epidemic. The objective of this work was to compare HIV prevalence trend using National ANC HSS data and PMTCT programme data in Gombe state over the last 10 years. Methodology: Cross-sectional comparative study. The HIV prevalence among pregnant women in Gombe State obtained from Gombe State PMTCT programme data from 2004-2014 was compared with the National Biennial sentinel survey for HIV in pregnant women attending ANC in the state over the same period. Results: Women tested for HIV during ANC in Gombe state increased from 4689 in 2004 to 74,737 in 2014. 447,732 women were cumulatively tested for HIV with a positivity rate of $2.1 \%$ (9543). ANC HIV positivity rates from PMTCT programme data witnessed a decline from $8.2 \%(385 / 4689)$ in 2004 to $0.6 \%(497 / 74,737)$ in 2014 . Conversely, the National biennial HIV sero-prevalence sentinel survey reports for Gombe state in 2005, 2006, 2008, 2010, 2012 and 2014 were 4.9\%, 4.4\%, 4.0\%, 4.2\%, 4.1\% and $3.4 \%$ respectively. The state PMTCT data showed a significant decline in HIV positivity rates among women, paralleled by increased testing, whereas
\end{abstract}


the national sero-prevalence survey averaged $4.2 \%$. Conclusion: While routine yearly Gombe state PMTCT programme data showed a declining HIV trend, biennially conducted seroprevalence in the state was consistent over the period. Implications are unclear to us; accurate estimation of HIV prevalence is a prerequisite for planning.

\section{Keywords}

Antenatal, HIV, Prevalence, PMTCT, Sero-Survey

\section{Introduction}

Trends in HIV prevalence are necessary to monitor the course of the epidemic, measure the effectiveness of control and prevention interventions, and plan further HIV control efforts. Timely and reliable data on HIV prevalence are gathered by HIV surveillance systems through the on-going systematic collection, analysis and reporting of data at different points in the HIV disease process [1] [2].

Since 1991, Nigeria's estimate of the HIV prevalence and burden has been through the conduct of biennial HIV sero-sentinel survey among pregnant women attending clinics throughout the country [3] [4]. In addition, National AIDS and reproductive health surveys (NARHS) provide further understanding of the dynamics of the disease in the country [5]. The National HIV prevalence declined from $4.1 \%$ in 2010 to $3.0 \%$ in 2014 with state, zonal and urban-rural variations [4] [5].

Antenatal clinics (ANCs) provide an accessible cross-section of healthy, sexually active women in the general population, and data from ANC HIV sero-sentinel survey (HSS) are considered to be generally representative of the underlying community [1] [2]. In many countries, national HIV prevalence estimates are substantially based on annual or biennial ANC HSS [1] [2] [3].

The Joint United Nations Programme on HIV/AIDS (UNAIDS)/World Health Organization (WHO) 2000 [6] and 2013 guidelines on second generation HIV surveillance [2] recommend conducting sero-survey among pregnant women as a core surveillance activity in concentrated and generalized HIV epidemics. Prevention Mother-to-Child Transmission of HIV (PMTCT) programmes in some sub Saharan Africa countries have witnessed substantial expansion in coverage (global report) [7] [8] [9]. As PMTCT programmes expand coverage and capture socio demographics, syphilis and HIV testing data similar to those collected by ANC HSS, many countries are considering the use of routinely collected PMTCT programme data to complement or replace ANC HSS [1] [2].

The World Health Organization (WHO) recommends that five areas be evaluated before a successful transition from ANC HSS to surveillance using routine antenatal HIV testing can be considered. These are: agreement between ANC SS 
and routine antenatal HIV test results; magnitude of selection bias in routine antenatal testing compared to ANC SS data; all ANC HSS sites that should provide routine antenatal HIV testing; the quality of routinely collected antenatal data and the state of routine HIV testing quality assurance practices [1].

Nigeria accounts for the $28 \%$ of the global burden of mother to child transmission of HIV with about 58,000 of infants delivered with HIV infection in 2014 [10] and there are significant regional and state variations in PMTCT programme implementation in the country [3] [4] [11]. Ebonyi State (Southeast Nigeria) was able to supersede the $80 \%$ coverage target while Nassarawa (Northcentral) Gombe (Northeast) and the Federal capital territory-Abuja had over $70 \%$ coverage. Seven states were unable to counsel and test up to $20 \%$ of pregnant women [11].

Since the inception of the PMTCT programme in Nigeria in 2002, of the 36 states in the country, Gombe State has consistently maintained its position as one of the three leading states in PMTCT coverage nationwide [11]. Also, the dried blood spot DNA-PCR for early infant diagnosis (EID) of HIV was first introduced within the State [11].

\section{Aim}

The aim of this report is to compare HIV prevalence trends using National ANC HSS and with that obtained from PMTCT programme data in Gombe state between 2004 and 2014.

\section{Methodology}

\section{Study Site}

\section{Gombe State}

Gombe state is one of the 6 states in North east Nigeria and one of the 36 in the country and has an estimated population of 3.0 million (Figure 1) [12].

There are 594 health facilities, of these, 21 general hospitals, 1 state owned specialist Hospital, 1 Federal Teaching Hospital, 68 private health facilities, and 517 government owned primary health facilities [13].

Women of child bearing age (15 - 49 years) are estimated as 666,260. The population of children aged 5 years and below is 605,691 (20\% of total population). The annual growth rate is $3.2 \%$. The total fertility rate is 7 [13]. Antenatal care provided by skilled Health workers is at 58.2\% [14].

\section{Study design}

This is a retrospective prevalence-based comparative study of national HIV sero-prevalence sentinel survey among pregnant women attending ANC in Gombe State and PMTCT routine data for the State from 2004-2014.

Gombe State agency for the control of AIDS (GOMSACA) was established in 2002 [15] [16]. The national HIV sero-prevalence sentinel survey was conducted by the Federal Ministry of Health, Nigeria among pregnant women attending ANC in Gombe state and initially involved two then subsequently four sites; with Gombe and Kaltungo as urban and Kwami and Zambuk as rural sites. The 


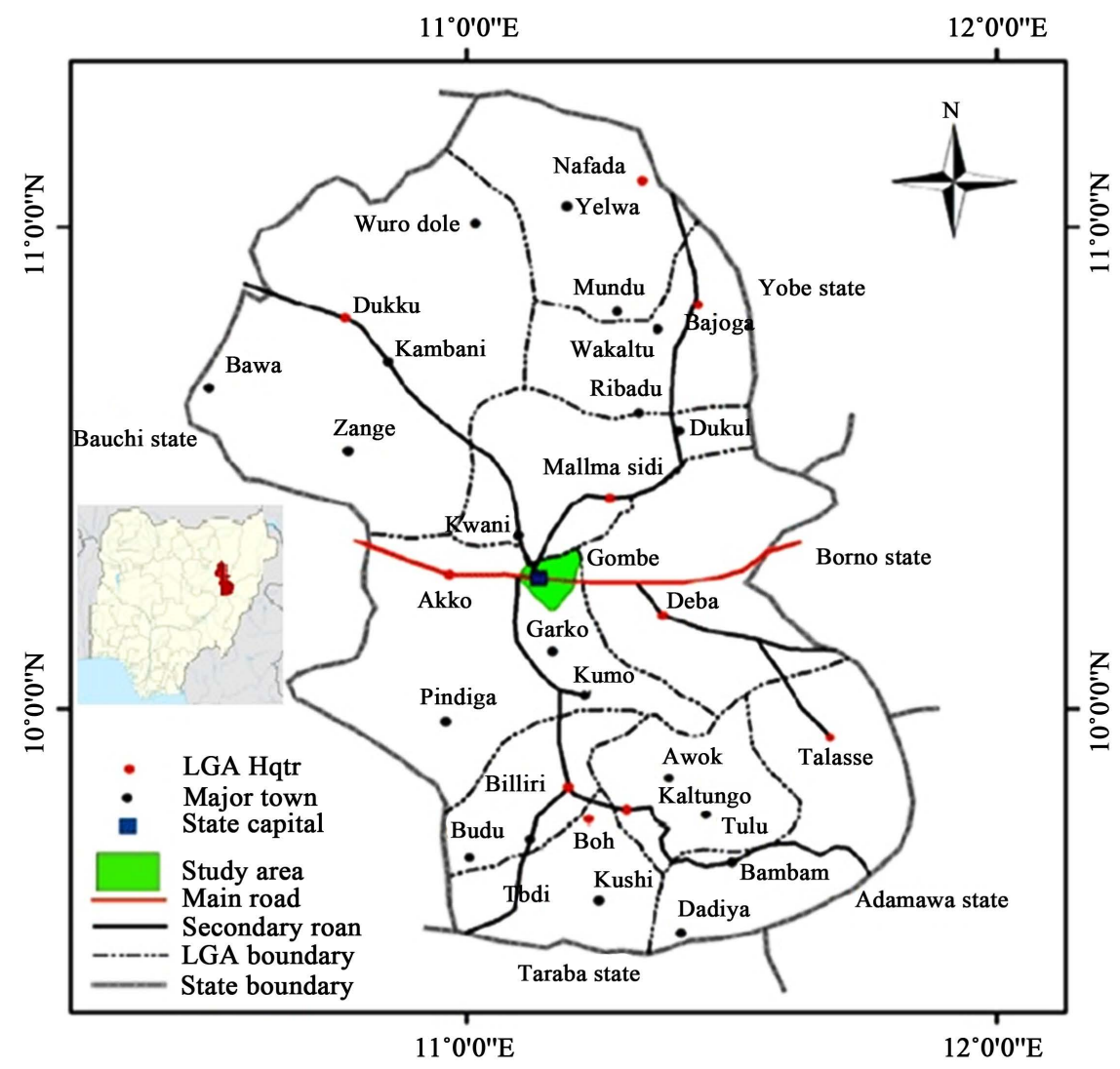

Figure 1. Map of Gombe State showing study area (Source: http://www.gombestate.gov.ng/).

HIV sentinel Survey was an unlinked anonymous HIV testing of 900 pregnant women in the 4 sites in Gombe state carried out in 2005, 2006, 2008, 2010, 2012 and 2014 [3] [4]. Women who participated in the sentinel survey were pregnant women of all ages, pregnancy was confirmed by health provider on-site, the women were attending ANC for the first time for that particular pregnancy and they accepted routine ANC test.

PMTCT services in Gombe State started in September 2004 in 9 health facilities and has been scaled up to involve 201 PMTCT sites currently. PMTCT data was collected from each facility records and reviewed the by State agency for the control of AIDS on a yearly basis from 2004 till 2014 [17]. HIV Group information and testing for PMTCT was followed by post-test counselling and opt- out was the strategy in all ANC clinics in the state [18]. Non laboratory staffs have been trained on HIV testing with quality control/assurance processes put in place [19]. HIV testing algorithm is serial testing using recommended HIV test kits with high sensitivity and specificity including Determine R, Unigold and Stat Pak [20].

A multi-disciplinary team formed in 2004 coordinates PMTCT services in Gombe State [17]. Coordinating teams were formed in all health facilities offering PMTCT services and regular coordination meeting, programme review sessions, quarterly monitoring and supportive supervisory meetings are held and 
partnerships were created with various non-governmental organisations [21]-[27]. Health care workers at all levels including doctors, nurses/midwives, laboratory staff community extension workers received training and retraining in PMTCT using national training tools [28]-[42].

\section{Results}

From September 2004 to 2014, 482,730 pregnant women were counselled and tested in 201 sites during ANC in Gombe State. During this period, 447,732 pregnant women were tested for HIV (Table 1). This gave a HIV acceptance testing rate of $92.7 \%$ cumulatively. There has been increasing acceptance of HIV testing among pregnant women from $54.7 \%$ in 2004 to a peak of $99.3 \%$ in 2012 and $97.2 \%$ in 2014 (Table 1). Of the 447,732 pregnant women tested for HIV from 2004-2014, 9543 were HIV positive with a cumulative prevalence of $2.1 \%$ (Table 1). As many more PMTCT sites were established in Gombe state, women tested for HIV during ANC increased from 4689 in 2004 to 79,488 in 2013. The number of health facilities offering PMTCT services increased from 9 in 2004 to 201 in 2014. There was a steady decline in HIV prevalence in pregnant women from $8.2 \%$ in 2004 to $0.6 \%$ in 2014 (Table 1).

The number of sites for the National HIV sero-sentinel survey in Gombe state remained 2 rural and 2 urban sites over the last 10 years. Also, the number of pregnant women tested during the HSS remained at 900 (Table 2). Although the prevalence of HIV among pregnant women in 2005 obtained from Gombe State PMTCT data was higher than Sero-sentinel survey (7.5\% vs $4.9 \%)$; the State PMTCT HIV prevalence rate demonstrated a steady decline till 2014 (Figure 2). From 2005-2012, the National HSS prevalence for Gombe state was consistently up to $4 \%$, with a slight decline to $3.4 \%$ in 2014 (Figure 2). HIV prevalence for Gombe state PMTCT programme data and ANC HSS were $0.6 \%$ and $3.4 \%$ respectively in 2014 (Figure 2).

Table 1. Gombe State PMTCT programme data (2004-2014).

\begin{tabular}{ccccccc}
\hline Year & $\begin{array}{c}\text { PMTCT } \\
\text { sites }\end{array}$ & $\begin{array}{c}\text { Pregnant } \\
\text { women } \\
\text { counselled }\end{array}$ & $\begin{array}{c}\text { Pregnant } \\
\text { women } \\
\text { tested for HIV }\end{array}$ & $\begin{array}{c}\text { HIV test } \\
\text { acceptance } \\
\text { rate }(\%)\end{array}$ & $\begin{array}{c}\text { HIV positive } \\
\text { pregnant } \\
\text { women }\end{array}$ & $\begin{array}{c}\text { Percentage } \\
\text { HIV } \\
\text { positive (\%) }\end{array}$ \\
\hline 2004 & 9 & 8567 & 4689 & 54.7 & 385 & 8.2 \\
2005 & 18 & 9453 & 6969 & 73.7 & 525 & 7.5 \\
2006 & 58 & 14,038 & 12,619 & 89.8 & 613 & 4.8 \\
2007 & 66 & 28,076 & 25,648 & 91.3 & 588 & 2.2 \\
2008 & 85 & 50,956 & 48,088 & 94.3 & 1298 & 2.7 \\
2009 & 89 & 14,038 & 58,748 & 91.3 & 1438 & 2.4 \\
2010 & 107 & 45,068 & 35,438 & 78.6 & 886 & 2.5 \\
2011 & 129 & 56,776 & 54,678 & 96.3 & 1421 & 2.6 \\
2012 & 169 & 46,999 & 46,630 & 99.3 & 968 & 2.0 \\
2013 & 224 & 81,657 & 79,488 & 97.3 & 924 & 1.1 \\
2014 & 201 & 76,815 & 74,737 & 97.2 & 497 & 0.6 \\
Total & & 482,730 & 447,732 & 92.7 & 9543 & 2.1 \\
\hline
\end{tabular}




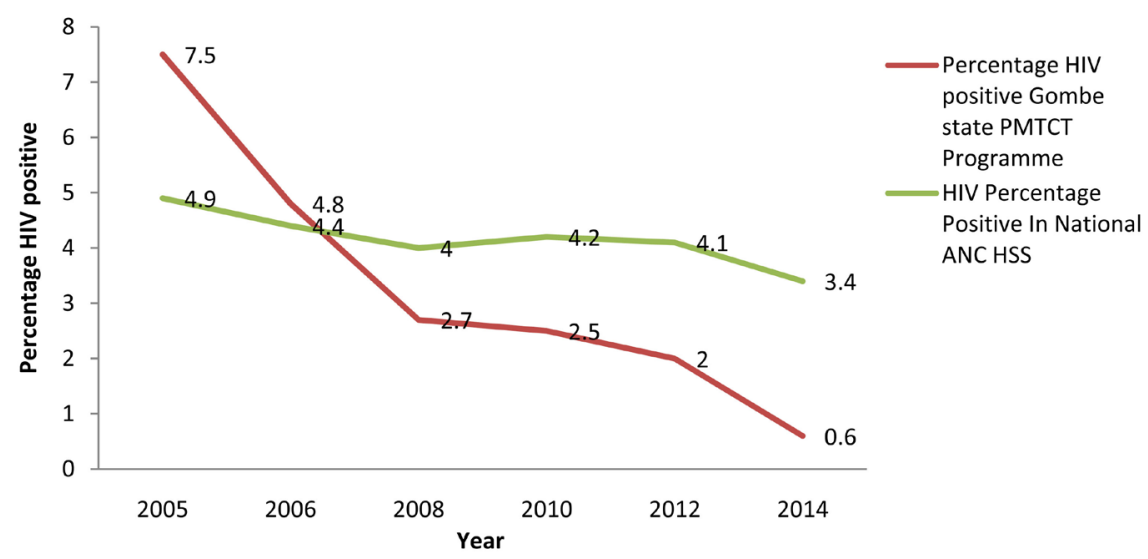

Figure 2. Comparison of HIV prevalence rate in Gombe State PMTCT programme and National Sero-sentinel Survey figures for Gombe State, 2005-2014.

Table 2. National ANC HIV Sero-prevalence sentinel survey for Gombe State.

\begin{tabular}{cccc}
\hline Year ANC HSS & $\begin{array}{c}\text { ANC sites } \\
\text { for HSS }\end{array}$ & $\begin{array}{c}\text { Number of Pregnant } \\
\text { Women Tested For HSS }\end{array}$ & $\begin{array}{c}\text { HIV Percentage } \\
\text { Positive In ANC HSS }\end{array}$ \\
\hline 2005 & 4 & 900 & 4.9 \\
2006 & 4 & 900 & 4.4 \\
2008 & 4 & 900 & 4.0 \\
2010 & 4 & 900 & 4.2 \\
2012 & 4 & 900 & 4.1 \\
2014 & 4 & 900 & 3.4 \\
\hline
\end{tabular}

\section{Discussion}

To our knowledge, this study is the first to compare the State HIV PMTCT programme data with ANC HSS data over a 10 -year period in Nigeria. Nigeria is currently witnessing a scale up in PMTCT programmes with Gombe state as one of the three states in the country with PMTCT coverage of over $70 \%$ as at 2015 [11]. National PMTCT coverage is $30.2 \%$ [43].

Comparing ANC sentinel surveillance and PMTCT programme is relatively simple and can provide important information [43]. The utility of HIV prevalence data collected in PMTCT programmes for HIV monitoring and surveillance has been investigated [44]-[49] and is being considered with guidelines developed [1] [2] [50] [51]. ANC HSS raises certain ethical concerns in that it does not obtain informed consent from pregnant women tested for HIV, does not provide them their HIV test results and thus, they are not referred to available HIV care, treatment, and prevention of mother to child transmission (PMTCT) services if HIV test results are positive [1] [50]. Additionally, this ANC HSS model raises challenges in data standardization and designing reliable epidemiological surveillance models for low income countries [1] [47] [50].

High-quality PMTCT programme data could provide a cost-effective alternative to ANC HSS [47] [51]. The population of women captured by both systems 
is the same (i.e. pregnant women from the communities attending ANC). Epidemiologic information provided by HIV surveillance among pregnant women attending ANC, combined with other sources of surveillance data (e.g. household surveys, key population surveys, HIV case surveillance and surveillance of sexually transmitted infections [STIs]), allows surveillance programmes to address key aspects of the "know your epidemic" approach of second-generation surveillance of HIV [47] [50] [51]. These aspects include understanding changes in the direction of the epidemic, understanding subnational variations in an epidemic and identifying localized geographical areas with higher burdens of HIV [2] [50]. While the WHO recommends that five areas be evaluated before a successful transition from ANC HSS to surveillance using routine antenatal HIV testing can be considered, mature PMTCT programmes at subnational levels can provide reliable data to inform decision making at the national levels [50].

The Gombe state PMTCT program has achieved over 70\% [11] coverage; therefore comparing trends in PMTCT programme data and ANC HSS becomes feasible [1] [50]. The number of PMTCT sites in the state has increased rapidly from 2006 with greater representativeness especially as the number of PMTCT sites increased from urban to rural sites and decentralization from secondary health facilities to primary health care centres.

The ANC HSS sites in Gombe state remained largely unchanged in number and pregnant women tested anonymously for HIV. From 2008, HIV prevalence data in our PMTCT programme was consistently lower than that of the ANC HSS. While the Gombe state PMTCT HIV prevalence data showed a steady decline from $7.5 \%$ in 2005 to $0.6 \%$ in 2014 , the ANC HSS programme data remained fairly constant hovering around $4 \%$. In addition, the HIV acceptance testing rate among new ANC attendees increased from 73.7\% in 2005 to $97.2 \%$ in 2014.

The scaling up of HIV testing by non-laboratory staff is a major factor in uptake and demonstrated increased coverage of over 70\%; this was supported by effective quality assurance and quality control processes supervised by laboratory scientists. Mirkuzie et al. [52] compared PMTCT and ANC HSS data in Ethiopia over 2 years and concluded that PMTCT data can be used to monitor HIV trends. HIV prevalence rate in the 2 groups studied by the Ethiopian researchers were $6.2 \%$ and $4.5 \%$ and $6.1 \%$ and $5.5 \%$ in 2008 and 2009 respectively [52]. Their study was however limited by the short duration (2008-2009) and low coverage. Similarly in a study whose duration was short and PMTCT coverage varied between $6 \%$ and $76 \%$ Kumar et al. [53] reported that routinely collected PMTCT has potential for reliable HIV time trends in India after comparing PMTCT and ANC HSS data from 2005 and 2007. In a Rwandan study [54] involving 27 sites evaluated in 2011 and 2013, routine PMTCT program data were recommended to serve as the basis for antenatal clinic HIV surveillance because of the universal acceptance of HIV testing, relatively low prevalence of HIV among pregnant women, high data quality, and high coverage HIV testing at the 
health facility level. Reports from Zimbabwe [55], Kenya [56] and Cameroon [57] have however suggested the need for additional preparation including strengthening quality assurances of HIV rapid testing and data quality practices before transitioning to PMTCT data for HIV surveillance.

\section{Conclusion \& Recommendations}

Gombe state PMTCT programme coverage is high and increasing with high HIV testing acceptance rate. As HIV testing service quality and regular data quality assessment and validation are strengthened in the wake of decentralization, the HIV prevalence data of the Gombe state PMTCT programme has progressively become lower than the National ANC HSS. While the implications for these observations are unclear, accurate estimate of HIV prevalence and burden is critical determinants for planning of impactful interventions.

A sub-regional wide evaluation of PMTCT programme data and ANC HSS in countries with high PMTCT coverage is recommended to guide transitioning from the use of ANC HSS to PMTCT programme data for HIV trend estimation.

\section{Limitations}

A larger national or sub-regional study would have been better able to demonstrate the comparison between ANC HSS and PMTCT data across a larger subset of Nigeria's population. However, due to the wide disparity in PMTCT coverage between states and various regions in the country, that was not feasible.

\section{Acknowledgements}

\section{Author Contributions}

IE: Conceived of the study and study design, conducted quantitative data analysis, developed the first manuscript draft, and critically reviewed the final manuscript.

MA: Oversaw the study design and conducted quantitative data analysis.

AS: Oversaw the study design and critically reviewed and conducted quantitative data analysis.

AA \& OC: Developed the first manuscript draft, conducted quantitative data analysis and critically reviewed the final manuscript.

We also wish to acknowledge Dr Abiola Davies, Dr Noma Owens and Dr Susan Ojomo all of UNICEF Nigeria for their support to the Gombe State PMTCT programme since its commencement in 2004. Ibrahim Hassan, the then state AIDS programme coordinator in the Gombe State Ministry of Health, Alhaji Isa Yahaya and Mr Enoch of the UNICEF assisted programme office. Gombe State Agency for the control of AIDS, Ministry of Health Gombe State, Ministry for Local Government Gombe state, traditional rulers, Gombe Media Corporation, Nigerian Television Authority, Axios donation programme, Clinton Health Access Initiative, PEPFAR implementing partners ICAP/CIHP, FHI360, FGHIN in Gombe state are also acknowledged. 


\section{Source of Funding}

I. E and M. A have both received consultant fees and honoraria from UNICEF, PEPFAR implementing partners, CIHP and FHI360. Gombe state PMTCT programme receives support from CIHP. The Antenatal sentinel surveillance survey is sponsored by the Federal ministry of Health.

\section{Conflicts of Interest}

The authors declare no conflicts of interest regarding the publication of this paper.

\section{References}

[1] World Health Organization (2013) Surveillance Guidelines for Assessing the Utility of Data from Prevention of Mother-to-Child Transmission (PMTCT) Programmes for HIV Sentinel Surveillance among Pregnant Women. UNAIDS/WHO Working Group on Global HIV/AIDS and STI Surveillance. https://www.who.int/hiv/pub/surveillance/2013package/module3/en

[2] World Health Organization (2013) Guidelines for Second Generation HIV Surveillance: An Update: Know Your Epidemic.

https://www.who.int/hiv/pub/surveillance/2013package/module1/en

[3] Federal Ministry of Health (1991) Technical Report: National HIV/Syphilis Sero-Prevalence Sentinel Survey among Pregnant Women Attending Antenatal Clinics in Nigeria. Federal Ministry of Health, Abuja.

[4] Federal Ministry of Health (2014) Technical Report: National HIV Sero-Prevalence Sentinel Survey among Pregnant Women Attending Antenatal Clinics in Nigeria. Federal Ministry of Health, Department of Public Health National AIDS/STI Control Programme, Abuja.

[5] Federal Ministry of Health (2012) National HIV/AIDS and Reproductive Health Survey. (NARHS Plus II, 2012) Federal Ministry of Health, Department of Public Health National AIDS/STI Control Programme, Abuja.

[6] World Health Organization (2000) Second Generation Surveillance for HIV: The Next Decade, World Health Organization and Joint United Nations Programme on HIV/AIDS. https://www.who.int/hiv/pub/surveillance/2013package/module1/en

[7] World Health Organization (2010) PMTCT Strategic Vision 2010-2015: Preventing Mother-to-Child Transmission of HIV to Reach the UNGASS and Millennium Development Goals. World Health Organization, Geneva, 1-40.

http://www.who.int/hiv/pub/mtct/strategic_vision.pdf

[8] Joint United Nations Programme on HIV/AIDS (UNAIDS) Global Report: UNAIDS Report on the Global AIDS Epidemic.

http://www.unaids.org/en/media/unaids/contentassets/documents/epidemiology/20 13/gr2013/UNAIDS_Global_Report_2013_en.pdf

[9] Joint United Nations Programme on HIV/AIDS (UNAIDS) (2015) Global Aids Response Progress Reporting 2015.

[10] Joint United Nations Programme on HIV/AIDS (UNAIDS) (2012) A Progress Report on the Global Plan: Towards the Elimination of New HIV Infections among Children by 2015 and Keeping Their Mothers Alive.

http://www.who.int/woman_child_accountability/ierg/reports/UNAIDS_ProgressR eportGlobalPlan_FINAL_July17_Web.pdf 
[11] Federal Ministry of Health, Nigeria (2015) National AIDS \& STI's Control Programme Annual Report on HIV/AIDS Health Sector Response in Nigeria.

[12] Gombe State, Nigeria. General Information. https://gombestate.gov.ng

[13] Gombe State, Nigeria (2015) Gombe State Human Resources Strategic Plan. Gombe State Government.

[14] National Population Commission, Nigeria (2013) National Demograhic and Health Survey (NDHS) 2013. Abuja. https://dhsprogram.com/pubs/pdf/PR41/PR41.pdf

[15] Gombe State, Nigeria (2006) Gombe State HIV/AIDS Strategic Plan: 2006-2009. Gombe State Action Committee on HIV/AIDS (GOMSACA); Gombe.

[16] Gombe State, Nigeria (2012) Gombe State HIV/AIDS Strategic Plan (SSP) 2010-2015 and Joint Annual Review (JAR) 2012. Gombe State Action Committee on HIV/AIDS (GOMSACA); Gombe.

[17] Gombe State, Nigeria (2017) PMTCT First Quarter Report. Gombe State Action Committee on HIV/AIDS (GOMSACA). Gombe.

[18] Isaac, E.W., Jibrin, Y.B., Massa, A.A., Davies, A., Ojomo, S., Owens, N., Hassan, I., Medina, E., Waziri, A., Maina, L., Yahaya, I., Ishaku, S. and Eliazar, E. (2005) VCCT Uptake: Group Individual Pre-Test Counselling in Gombe State PMTCT Programme: Some Preliminary Observations from Gombe State PMTCT Programme. 14th ICASA Conference, Abuja, Abstract No. ThPoB00383.

[19] Isaac, E.W., Massa, A.A., et al. (2008) PMTCT Scale Up: Accuracy of HIV Testing by Non-Laboratory Staff in the Gombe State PMTCT Programme. 15th ICASA Conference, Dakar, Abstract No. 734/PEA03.

[20] Federal Ministry of Health (2014) Integrated National Guidelines for HIV Prevention, Treatment, and Care. FMoH, HIV/AIDS Division, Abuja.

[21] Gombe State, Nigeria (2008) Fact Sheet on Gombe State HIV/AIDS Response; Annual Report 2008. Gombe State Action Committee on HIV/AIDS (GOMSACA).

[22] Gombe State, Nigeria (2013) Gombe State HIV/AIDS Coordination and Partnership Guidelines, 2013. Gombe State Action Committee on HIV/AIDS (GOMSACA).

[23] Gombe State AIDS and STI's Control Program. (SASCP) Gombe State 1st Annual PMTCT Report 2005. Gombe State.

[24] Gombe State, Nigeria (2012) HIV/AIDS Response Fact Sheet; 2012. Gombe State Action Committee on HIV/AIDS (GOMSACA).

[25] Federal Ministry of Health and UNICEF (2007) Training Manual on Advocacy and Community Mobilization in Support of the Prevention of Mother-to-Child Transmission of HIV.

[26] Federal Ministry of Health (FMOH), Nigeria and United Nations Children's Fund (UNICEF) (2007) Interpersonal Communication Skills in the Prevention of Mother-to-Child Transmission of HIV (PMTCT). Federal Ministry of Health, HIV/AIDS Division, Abuja.

[27] Federal Ministry of Health (FMOH), Nigeria (2005) National Guidelines on Prevention of Mother-to-Child Transmission of HIV (PMTCT). Federal Ministry of Health, HIV/AIDS Division, Abuja.

[28] Federal Ministry of Health (FMOH), Nigeria (2006) Prevention of Mother-to-Child Transmission of HIV (PMTCT). Nigeria Curriculum Participant Manual. Federal Ministry of Health, HIV/AIDS Division, Abuja.

[29] World Health Organization (WHO) (2006) Integrated Management of Pregnancy and Childbirth (IMAI-IMPAC). 
https://www.who.int/maternal_child_adolescent/topics/maternal/impac/en

[30] Federal Ministry of Health (FMOH), Nigeria (2006) National Guidelines for HIV/AIDS Counseling. Federal Ministry of Health, HIV/AIDS Division, Abuja.

[31] Federal Ministry of Health (2006) National Training Course on HIV Counseling and Testing. Federal Ministry of Health, HIV/AIDS Division, Abuja.

[32] World Health Organization (WHO) and United Nations Children's Fund (UNICEF) (1993) Breastfeeding Counselling: A Training Course.

https://www.who.int/maternal_child_adolescent/documents/pdfs/bc_participants_= $\underline{\text { manual.pdf }}$

[33] Federal Ministry of Health (FMOH), Nigeria (2006) National Tuberculosis, Leprosy and Buruli Ulcer Management and Control Guidelines. Federal Ministry of Health, Abuja.

[34] Federal Ministry of Health (FMOH), Nigeria (2007) National Guidelines on Prevention of Mother-to-Child Transmission of HIV (PMTCT). Federal Ministry of Health, HIV/AIDS Division, Abuja.

[35] Federal Ministry of Health (FMOH), Nigeria (2010) National Guidelines on Prevention of Mother-to-Child Transmission of HIV (PMTCT). Federal Ministry of Health, HIV/AIDS Division, Abuja.

[36] Federal Ministry of Health (FMOH), Nigeria (2007) National Guidelines for Paediatric HIV and AIDS Treatment and Care. Federal Ministry of Health, HIV/AIDS Division, Abuja.

[37] Federal Ministry of Health (2007) Standard Operating Procedures on Antiretroviral Therapy for Paediatric Patients. Federal Ministry of Health, HIV/AIDS Division, Abuja.

[38] Federal Ministry of Health (2010) National Training Course on Early Infant Diagnosis of HIV Infection: Trainers' Guide. FMoH, HIV/AIDS Division, Abuja.

[39] World Health Organization (WHO) (2013) Consolidated Guidelines on the Use of Anti-Retroviral Drugs for Treating and Preventing HIV Infection: Recommendations for a Public Health Approach. https://www.who.int/hiv/pub/guidelines/arv2013/en

[40] Federal Ministry of Health, Nigeria (2010) National Training Course on HIV Counseling and Testing. Federal Ministry of Health, HIV/AIDS Division, Abuja.

[41] Federal Ministry of Health (2010) National Tuberculosis and Leprosy Control Programme. (NTBLCP) National Tuberculosis, Leprosy and Buruli Ulcer Management and Control Workers Manual. 5th Edition, FMoH, Abuja. http://ntblcp.org.ng

[42] Federal Ministry of Health (2014) National Guidelines for HIV Prevention Treatment and Care.

[43] National Action Committee on AIDS (2016) Fact Sheet: Prevention of Mother to Child Transmission. NACA, Abuja. https://naca.gov.ng/factsheet-hiv-counseling-testing-hct-2016

[44] Fabiani, M., Yoti, Z., Nattabi, B., Ayella, E.O., Opio, A.A., Musinguzi, J., et al. (2007) Adjusting HIV Prevalence Data from a Program for the Prevention of Mother-to-Child Transmission for Surveillance Purposes in Uganda. Journal of Acquired Immune Deficiency Syndromes, 46, 328-331. https://doi.org/10.1097/QAI.0b013e31815724e7

[45] Ministry of Public Health and Sanitation, Kenya (2011) Utility of Prevention of Mother-to-Child HIV Transmission Program Data for HIV Surveillance in Kenya: Methods, Findings, and Recommendations. Kenya National AIDS and STD Control 
Program, Ministry of Public Health and Sanitation, Nairobi.

[46] Ministry of Public Health and Sanitation, Kenya (2010) Sentinel Surveillance for HIV and Syphilis among Pregnant Women, 2010. Kenya National AIDS and STI Control Program, Ministry of Public Health and Sanitation, Nairobi.

[47] Bolu, O., Anand, A., Swartzendruber, A., Hladik, W., Marum, L., Sheikh, A., et al. (2007) Utility of Antenatal HIV Surveillance Data to Evaluate Prevention of Mother-to-Child HIV Transmission Programs in Resource-Limited Settings. American Journal of Obstetrics \& Gynecology, 197, S17-S25. https://doi.org/10.1016/j.ajog.2007.03.082

[48] Kayibanda, F., Alary, M., Bitera, R., Mutagoma, M., Kabeja, A., Hinda, R., et al. (2011) Use of Routine Data Collected by the Prevention of Mother-to-Child Transmission Program for HIV Surveillance among Pregnant Women in Rwanda: Opportunities and Limitations. AIDS Care, 23, 1570-1577. https://doi.org/10.1080/09540121.2011.579941

[49] Marsh, K.A., Bolu, O., Bodika, S., Seipone, K., Wonkongkathep, S., Baryarama, F., et al. (2010) How Can PMTCT Program Data Be Used for the Purposes of HIV Surveillance? Journal of HIVAIDS Surveillance and Epidemiology, 2, 5.

[50] World Health Organisation (WHO) \& Joint United Nations Programme on HIV/AIDS (UNAIDS) (2015) UNAIDS/WHO Working Group on Global HIV/AIDS and STI Surveillance. Guidelines for Conducting HIV Surveillance among Pregnant Women Attending Antenatal Clinics Based on Routine Programme Data.

https://www.who.int/hiv/pub/guidelines/si-guidelines-pregnant-women/en

[51] World Health Organisation (WHO) \& Joint United Nations Programme on HIV/AIDS (UNAIDS) (2003) Reconciling Antenatal Clinic-Based Surveillance and Population-Based Survey Estimates of HIV Prevalence in Sub-Saharan Africa. WHO/UNAIDS, Geneva.

[52] Mirkuzie, A.H., Sisay, M.M., Hinderaker, S.G., Moland, K.M. and Mørkve, O. (2012) Comparing HIV Prevalence Estimates from Prevention of Mother-to-Child HIV Transmission Programme and the Antenatal HIV Surveillance in Addis Ababa. BMC Public Health, 12, Article No. 1113.

https://www.who.int/hiv/strategic/en/lusaka_report.doc https://doi.org/10.1186/1471-2458-12-1113

[53] Kumar, R., Virdi, N.K., Lakshmi, P., Garg, R., Bhattacharya, M. and Khera, A. (2010) Utility of Prevention of Parent-to-Child Transmission (PPTCT) Programme Data for HIV Surveillance in General Population. Indian Journal of Medical Research, 132, 256-259.

[54] Balisanga, H., Mutagoma, M., Remera, E., Kayitesi, C., Kayirangwa, E., Dee, J., et al. (2016) HIV Surveillance in Rwanda: Readiness Assessment to Transition from Antenatal Care-Based to Prevention of Mother-to-Child Transmission Program-Based HIV Surveillance. International Journal of Infectious Diseases, 52, 62-67. https://doi.org/10.1016/j.ijid.2016.08.029

[55] Gonese, E., Mushavi, A., Mungati, M., Mhangara, M., Dzangare, J., Mugurungi, O., et al. (2016) Is Zimbabwe Ready to Transition from Anonymous Unlinked Sero-Surveillance to Using Prevention of Mother to Child Transmission of HIV (PMTCT) Program Data for HIV Surveillance? Results of PMTCT Utility Study 2012. BMC Infectious Diseases, 16, Article No. 97. https://doi.org/10.1186/s12879-016-1425-2

[56] Sirengo, M., Rutherford, G.W., Otieno-Nyunya, B., Kellogg, T.A., Kimanga, D., Muraguri, N., et al. (2016) Evaluation of Kenya's Readiness to Transition from Sen- 
tinel Surveillance to Routine HIV Testing for Antenatal Clinic-Based HIV Surveillance. BMC Infectious Diseases, 16, Article No. 113.

https://doi.org/10.1186/s12879-016-1434-1

[57] Billong, S., Dee, J., Fokam, J., Nguefack-Tsague, G., Ekali, G., Fodjo, R., et al. (2017) Feasibility Study of HIV Sentinel Surveillance Using PMTCT Data in Cameroon: From Scientific Success to Programmatic Failure. BMC Infectious Diseases, 17, Article No. 3. https://doi.org/10.1186/s12879-016-2119-5 


\section{Abbreviations and Acronyms}

AIDS

ANC

ART

ARV

CBOs

EID

FCT

FGHIN

$\mathrm{FMOH}$

GOMSACA

HIV

HSS

HTS

ICAP

IHVN

LGA

$M \& E$

NACA

NGOs

PHCs

PEPFAR

PMTCT

$\mathrm{SMOH}$

UNICEF

WHO
Acquired Immunodeficiency Syndrome

Antenatal Care

Antiretroviral therapy

Antiretroviral (drug)

Community based Organisation

Early Infant Diagnosis

Federal Capital Territory

Friends for Global Health Initiative Nigeria

Federal Ministry of Health

Gombe State agency for the control of AIDS

Human Immunodeficiency Virus

HIV Sero-sentinel Survey

HIV Testing Services

International Centre for AIDS Prevention

Institute of Human Virology of Nigeria

Local Government Area

Monitoring and Evaluation

National Agency for the Control of AIDS

Non-Governmental Organisation

Primary Health Care Center

President's Emergency Plan for AIDS Relief

Prevention Mother-to-Child Transmission of HIV

State Ministry of Health

United Nations Children's Fund

World Health Organisation 